\title{
HUBUNGAN PENGETAHUAN IBU HAMIL TENTANG PERAWATAN PAYUDARA TERHADAP SIKAP PERAWATAN PAYUDARA SAAT KEHAMILAN DI PUSKESMAS XIII KOTO KAMPAR TAHUN 2018
}

\author{
Elvina $^{1}$ \\ ${ }^{1}$ Program Studi D IV Bidan Pendidik STIKes Karimun, Batam \\ Email: elvina.nsj@gmail.com
}

Masuk: 05-11-2019, revisi: 04-03-2020, diterima untuk diterbitkan: 04-06-2020

\begin{abstract}
ABSTRAK
Payudara adalah organ reproduksi wanita dan pada masa laktasi akan mengeluarkan air susu. Perawatan payudara selama kehamilan merupakan bagian penting yang harus diperhatikan sebagai persiapan dalam pemberian air susu ibu. Tetapi sebagian besar ibu hamil tidak melakukan perawatan payudara karena kurangnya pengetahuan dalam perawatan payudara itu sendiri.Penelitian ini bertujuan untuk mengetahui hubungan pengetahuan ibu hamil tentang perawatan payudara terhadap sikap perawatan payudara saat kehamilan di Puskesmas XIII Koto Kampar. Desain penelitian Deskriptif kuantitatif. Populasi dalam penelitian ini adalah seluruh ibu hamil yang datang ke XIII Koto Kampar berjumlah 98 orang.Teknik pengambilan sampel pada penelitian ini menggunakan Purposive sampling. Dimana sampel pada penelitian ini sebanyak 21 responden. Hasil penelitian dari 21 responden, pengetahuan ibu hamil tentang perawatan payudara dengan kriteria baik sebanyak 15 orang 71,4\%, sedangkan sikap perawatan payudara dengan kriteria baik sebanyak 12 orang 57,1\%. Dari hasil analisis dengan menggunakan chi-square didapatkan bahwa ada hubungan yang signifikan antara pengetahuan ibu hamil tentang perawatan payudara terhadap sikap perawatan payudara saat kehamilan dengan hasil uji chi-square diperoleh nilai $\rho<0,05$ yaitu 0,003 . Saran dari penelitian ini diharapkan bagi petugas kesehatan agar dapat memberikan informasi lebih dini dan mengajarkan pada ibu hamil tentang pelaksanaan perawatan payudara selama masa kehamilan.
\end{abstract}

Kata Kunci: payudara; pengetahuan; sikap

\begin{abstract}
The breast is a female reproductive organ and during lactation will secrete milk. Breast care during pregnancy is an important part that must be considered in preparation for breastfeeding. But the majority of pregnant women do not do breast care because of lack of knowledge in breast care itself. This study aims to determine the relationship of knowledge of pregnant women about breast care to the attitude of breast care during pregnancy at Puskesmas XIII Koto Kampar. Descriptive quantitative research design. The population in this study were all pregnant women who came to XIII Koto Kampar totaling 98 people. The sampling technique in this study uses purposive sampling. Tthe sample in this study were 21 respondents. The results of the study of 21 respondents, knowledge of pregnant women about breast care with good criteria as many as 15 people $71.4 \%$, while the attitude of breast care with good criteria as many as 12 people 57.1\%. From the results of the analysis using chi-square found that there is a significant relationship between the knowledge of pregnant women about breast care with breast care attitudes during pregnancy with the results of the chi-square test obtained value $\rho<0.05$ is 0.003 . Suggestions from this study are expected for health workers to be able to provide information early and teach pregnant women about implementing breast care during pregnancy.
\end{abstract}

Keywords: attitude; breast; knowledge

\section{PENDAHULUAN}

Payudara adalah organ reproduksi wanita dan pada masa laktasi akan mengeluarkan air susu. Banyak yang tidak mengetahui apa saja yang harus dilakukan terhadap kesehatan payudara (Saryono dan Pramitasari, 2009). Perawatan payudara selama kehamilan adalah merupakan bagian penting yang harus diperhatikan sebagai persiapan dalam pemberian air susu ibu. Banyak ibu yang mengeluh bayinya tidak mau menyusu, biasanya ini disebabkan oleh faktor teknis seperti puting susu yang masuk atau posisi menyusui yang salah. Dalam meningkatkan pemberian ASI pada bayi, ibu-ibu membutuhkan bantuan dan informasi serta dukungan agar 
merawat payudara pada saat hamil untuk mempersiapkan ASI pada saat melahirkan sehingga menambah keyakinan bahwa mereka dapat menyusui bayinya dengan baik dan mengetahui fungsi dan manfaat perawatan payudara pada saat hamil (Nurhati, 2009). Tidak sedikit calon ibu hamil yang mengabaikan perawatan payudara saat hamil, baik itu karena malas atau mungkin belum mengetahui manfaat merawat payudara akan berpengaruh saat menyusui (Nugroho, 2014).

Perawatan payudara selama hamil (Prenatal Breast Care) adalah perlakuan yang diberikan kepada payudara untuk persiapan menyusui dengan tujuan memudahkan bayi menghisap ASI, untuk menjaga kesehatan payudara, sehingga mencegah gangguan yang bisa timbul selama menyusui (Manuaba, 2010). Perawatan payudara merupakan salah satu bagian penting yang harus diperhatikan sebagai persiapan untuk menyusui nantinya, hal ini dikarenakan payudara merupakan organ esensial penghasil ASI yaitu makanan pokok bayi baru lahir sehingga perawatannya harus dilakukan sedini mungkin. Sebagian besar para ibu hamil tidak melakukan perawatan payudara karena kurangnya pengetahuan dalam perawatan payudara itu sendiri, Kurangnya infomasi tentang perawatan payudara seperti putting susu tidak menonjol, atau datar, karena keadaan buah dada khususnya puting susu merupakan salah satu faktor yang menentukan keberhasilan proses laktasi, kurangnya kesadaran para ibu akan pentingnya perawatan payudara selama kehamilan, tidak adanya dukungan dari keluarga untuk melakukan perawatan payudara sejak masa kehamilan, dan belum diberikannya pendidikan kesehatan oleh petugas kesehatan tentang perawatan payudara selama kehamilan. Ibu-ibu membutuhkan bantuan dan informasi serta dukungan dari segala pihak agar merawat payudara pada saat hamil untuk mempersiapkan ASI pada saat melahirkan sehingga menambah keyakinan bahwa mereka dapat menyusui bayinya dengan baik dan mengetahui fungsi dan manfaat perawatan payudara pada saat hamil.

Selama kehamilan payudara akan membengkak dan daerah sekitar putting warnanya akan lebih gelap. Keadaan payudara yang bengkak ini, payudara menjadi mudah teriritasi bahkan mudah luka. Ibu-ibu hamil tidak akan mengalami kesulitan dalam pemberian ASI bila sejak awal telah mengetahui bagaimana perawatan payudara (breast care) yang tepat dan benar. Ibu hamil yang tidak melakukan perawatan payudara selama kehamilan dan perawatan tersebut hanya dilakukan pasca persalinan, maka akan menimbulkan beberapa permasalahan, seperti puting susu tenggelam sehingga bayi sulit menghisap, ASI tidak keluar, produksi ASI sedikit dan tidak cukup dikonsumsi bayi, dan payudara kotor (Rahayu, 2012). Beberapa permasalahan yang timbul pada ibu hamil yang tidak melakukan perawatan payudara selama kehamilan tersebut, dapat mengakibatkan bayi tidak mau menyusu atau tidak mendapatkan ASI yang maksimal dari ibunya. Keadaan ini akan mengakibatkan kebutuhan gizi bayi tidak akan terpenuhi secara baik dan bayi akan mudah terkena penyakit, bahkan mengalami kematian (Saryono dan Pramitasari, 2009).

Pemberian ASI secara eksklusif dapat meminimalisir banyaknya kasus kurang gizi pada anak anak berusia dibawah 2 tahun yang sempat melanda beberapa wilayah Indonesia. Pada usia tersebut, bayi memiliki masa pertumbuhan dan perkembangan yang pesat, sehingga sering diistilahkan sebagai periode emas sekaligus periode kritis. Berdasarkan laporan dari Survei Demografi dan Kesehatan Indonesia diusia lebih dari 25 tahun sepertiga wanita di Dunia (38\%) didapati tidak menyusui bayinya sehingga terjadi pembengkakan payudara.

Pemberian ASI eksklusif terhadap bayi di Kabupaten Kampar tahun 2014 yaitu 39,4\% dimana wilayah kecamatan XIII Koto Kampar dengan jumlah bayi yang diberi ASI eksklusif paling tinggi. Angka ini masih sangat rendah bila dibandingkan dengan target nasional yaitu $80 \%$. Tidak tercapainya pemberian ASI eksklusif dikarenakan pertama faktor perilaku masyarakat 
yang beranggapan bila bayi menangis menandakan bahwa bayi lapar dan harus di beri makan, kedua karena dengan pemberian ASI eksklusif, bayi tidak dapat ditinggal kerja (wanita karier). Pada tahun 2013 sebanyak 34,9\% bayi yang mendapat ASI eksklusif. (Dinkes, 2014)

Berdasarkan data Puskesmas XIII Koto Kampar 2018 terdapat 98 ibu hamil yang melakukan pemeriksaan ANC yang diambil dari bulan Oktober 2018. Berdasarkan survey pendahuluan yang telah dilakukan oleh peneliti pada bulan Oktober di Puskesmas XIII Koto Kampar Tahun 2018. Hasil wawancara yang telah dilakukan pada 8 ibu hamil, ternyata didapatkan 5 orang ibu hamil tidak mengetahui cara melakukan perawatan payudara, dan 3 orang mengetahui dan sudah melaksanakan perawatan payudara.

Berdasarkan data di atas, penulis merasa tertarik untuk melakukan penelitian dengan judul "Hubungan Pengetahuan Ibu Hamil Tentang Perawatan Payudara Terhadap Sikap Perawatan Payudara Saat Kehamilan di Puskesmas XIII Koto Kampar tahun 2018”

\section{METODE PENELITIAN}

Tujuan Penelitain ini adalah untuk mengetahui Hubungan Pengetahuan Ibu Hamil Tentang Perawatan Payudara Terhadap Sikap Perawatan Payudara Saat Kehamilan di Puskesmas XIII Koto Kampar Tahun 2018. Populasi yang digunakan dalam penelitian ini adalah semua atau seluruh ibu hamil yang berkunjung ke Puskesmas XIII Koto Kampar pada bulan Oktober yang berjumlah $98 \mathrm{ibu}$ hamil. Teknik pengambilan sampel dalam penelitian ini adalah Purposive sampling yaitu salah satu teknik sampling di mana peneliti menentukan pengambilan sampel dengan cara menetapkan ciri-ciri khusus yang sesuai dengan tujuan penelitian yang berjumlah 21 orang ibu hamil dengan ciri-ciri ibu hamil Trimester III. Data dikumpulkan dengan menggunakan kuesioner.

Analisis Data Variabel penelitian yang digunakan adalah variabel bebas pengetahuan ibu hamil tentang perawatan payudara sedangkan variabel dependen adalah sikap perawatan payudara, analisi data yang digunakan adalah analisis univariat, dan bivariat Bila nilai $\mathrm{p}>0,05$ maka Ho diterima berarti tidak ada hubungan yang signifikan antara sikap perawatan payudara dengan pengetahuan. Bila nilai $\mathrm{p}<0,05$ maka Ha di terima berarti ada hubungan yang signifikan antara pengetahuan dengan sikap perawatan payudara.

\section{HASIL DAN PEMBAHASAN}

\section{a. Hasil penelitian}

Hasil penelitian yang telah dilakukan melalui pengisian kuesioner oleh ibu hamil yang datang ke Puskesmas XIII Koto Kampar pada bulan November 2018. Jumlah responden dalam penelitian ini adalah 21 orang ibu hamil yang datang ke Puskesmas XIII Koto Kampar tahun 2018. setelah kuesioner dikumpulkan, diolah dan di analisa secara manual dan selanjutnya hasil penelitian akan disajikan dalam tabel frekuensi sebagai berikut:

Tabel 1.Distribusi frekuensi pengetahuan

\begin{tabular}{c|c|c|cc}
\hline No & Kategori & Frekuensi (f) & Presentasi (\%) & \\
\hline 1 & Baik & 15 & $71,4 \%$ & \\
2 & Cukup & 6 & $28,6 \%$ & \\
3 & Kurang & 0 & $0 \%$ & $100 \%$ \\
\hline \multicolumn{5}{c}{ Jumlah } \\
\multicolumn{5}{c}{ Sumber: hasil penelitian bulan November 2018 }
\end{tabular}


Berdasarkan data dari tabel di atas dapat diketahui bahwa bila dilihat dari pengetahuan, yang dikategorikan baik sebanyak 15 orang $(71,4 \%)$, sedangkan yang dikategorikan berpengetahuan cukup sebanyak 6 orang $(28,6 \%)$, dan yang dikategorikan berpengetahuan kurang sebanyak 0 orang $(0 \%)$.

Tabel 2 Distribusi Fruekuensi sikap ibu hamil

\begin{tabular}{c|c|c|c}
\hline No & Kategori & $\begin{array}{c}\text { Frekuensi } \\
\text { (f) }\end{array}$ & $\begin{array}{c}\text { Presentasi } \\
(\%)\end{array}$ \\
\hline 1 & Baik & 12 & $57,1 \%$ \\
\hline 2 & Cukup & 7 & $33,3 \%$ \\
\hline 3 & Kurang & 2 & $9,5 \%$ \\
\hline & Jumlah & 21 & $100 \%$ \\
\hline
\end{tabular}

Sumber : hasil penelitian bulan November 2018

Berdasarkan data dari tabel diatas dapat diketahui bahwa bila dilihat dari sikap, yang dikategorikan baik sebanyak 12 orang $(57,1 \%)$, sedangkan yang dikategorikan sikap cukup sebanyak 7 orang $(33,3 \%)$, dan yang dikategorikan sikap kurang sebanyak 2 orang $(9,5 \%)$.

Tabel 3. Hubungan Pengetahuan ibu hamil tentang perawatan payudara terhadap sikap perawatan payudara

\begin{tabular}{|c|c|c|c|c|c|c|c|c|c|c|}
\hline \multirow{3}{*}{ Pengetahuan } & \multicolumn{6}{|c|}{ Sikap } & \multirow{3}{*}{$\mathrm{N}$} & \multirow{3}{*}{$\%$} & \multirow{3}{*}{$X^{2}$} & \multirow{3}{*}{$\mathrm{P}$} \\
\hline & \multicolumn{2}{|c|}{ Baik } & \multicolumn{2}{|c|}{ Cukup } & \multicolumn{2}{|c|}{ Kurang } & & & & \\
\hline & $\mathrm{n}$ & $\%$ & $\mathrm{n}$ & $\%$ & $\mathrm{n}$ & $\%$ & & & & \\
\hline Baik & 10 & 47.6 & 3 & 14.3 & 2 & 9.5 & 15 & 71.4 & & \\
\hline Cukup & 1 & 4.8 & 2 & 9.5 & 0 & 0 & 3 & 14.3 & 11550 & 0003 \\
\hline Kurang & 1 & 4.8 & 2 & 9.5 & 0 & 0 & 3 & 14.3 & 11.530 & 0,005 \\
\hline Total & 12 & 57.2 & 7 & 33.3 & 2 & 9.5 & 21 & 100 & & \\
\hline
\end{tabular}

Sumber : hasil penelitian bulan November 2018

Berdasarkan tabel 3 Dengan menggunakan analisis SPSS 25 menggunakan Chi-square didapatkan nilai $\rho$ Value $=11.550^{\mathrm{a}}$ sehingga $\rho$ value $=0,003$ maka hasil yang didapat lebih kecil dari pada rumus, maka terdapat hubungan antara pengetahuan ibu hamil tentang perawatan payudara terhadap sikap perawatan payudara. Penelitian yang dikakukan pada ibu hamil di puskesmas XIII Koto Kampar tahun 2018. Pembahasan dari hasil penelitian ini dapat dilihat dibawah ini.

\section{b. Pembahasan Analisis Univariat}

\section{- Pengetahuan}

Berdasarkan hasil penelitian yang telah dilakukan oleh peneliti di ketahui bahwa dari 21 responden, diketahui bahwa pengetahuan responden tentang perawatan payudara yang paling banyak dikategorikan baik sebanyak 15 orang $(71,4 \%)$. Pengetahuan ibu hamil baik karena ibu sudah mengetahui tentang payudara dan bagaimana cara merawat payudara, sehingga ibu tidak mengalami masalah-masalah saat menyusui karena ibu selalu menjaga kebersihan payudara terutama kebersihan putting susu. Ibu juga sudah mengetahui untuk tidak membersihkan putting susu dengan alkohol karena akan menyebabkan puting susu lecet. Sesuai dengan penelitian Wulandarai (2012) hasil penelitian menunjukkan 26 responden $(53,1 \%)$ dengan pengetahuan Baik, 12 responden $(24,5 \%)$ dengan pengetahuan cukup dan 11 responden $(22,4 \%)$ dengan pengetahuan yang kurang. 


\section{- Sikap}

Berdasarkan hasil Penelitian yang telah dilakukan oleh peneliti diketahui bahwa dari 31 Responden diketahui , Berdasarkan Penelitian dari tabel 4.2 di atas dapat diketahui bahwabila dilihatdari sikap responden tentang perawatan payudara, yang paling banyak dikategorikan baik sebanyak 12 orang $(57,1 \%)$. Sikap ibu hamil baik karena ibu sudah melakukan perawatan payudara selama ibu hamil, dan ibu yang bekerja pun menyempatkan diri untuk merawat payudara.Ibu juga setuju bila setiap bayi menerima ASI ekslusif. Sesuai dengan penelitian Vika (2012) hasil penelitian menunjukkan 23 responden $(46,9 \%)$ dengan perilaku baik, sedangkan 26 responden $(53,1 \%)$ mempunyai perilaku yang kurang dalam perawatan payudara

\section{c. Analisa Bivariat}

\section{- Hubungan PengetahuanIbu Hamil dengan Sikap Perawatan Payudara}

Analisis bivariat berfungsi untuk mengetahui hubungan pengetahuan ibu hamil tentang perawatan payudara terhadap sikap perawatan payudara. Sebelum menggunakan uji chi-square, dengan hasil Pengetahuan tentang Perawatan Payudara 71,4\% sedangkan Sikap Payudara dengan hasil $57,1 \%$ sehingga dihasilkan value $=11.550^{\text {a }}$ sehingga $\rho$ value $=0,003$. Jadi hasil yang didapatkan dari penelitian $\rho$ value lebih kecil dari nilai signifikan dengan menggunakan SPSS 25 . Ibu hamil sudah mengetahui bagaimana perawatan payudara yang baik sehingga sikap dalam pemberian ASI dan perawatan payudara juga baik. Ibu tidak mengalami malasah-masalah saat menyusui karena ibu selalu menjaga kebersihan payudara terutama kebersihan puting susu.

Sebagai hasil uji chi-square dengan menggunakan SPSS 25 didapat hasil $\rho$ value $<\alpha$ yaitu $0,003<0,05$ artinya hipotesis diterima dimana ada hubungan pengetahuan ibu hamil terhadap sikap perawatan payudara saat kehamilan di Puskesmas XIII Koto Kampar tahun 2018. Sesuai penelitian Wulandarai (2012) hasil penelitian menunjukkan 26 responden $(53,1 \%)$ dengan pengetahuan Baik, 12 responden (24,5\%) dengan pengetahuan cukup dan 11 responden $(22,4 \%)$ dengan pengetahuan yang kurang. 23 responden (46,9\%) dengan perilaku baik, sedangkan 26 responden $(53,1 \%)$ mempunyai perilaku yang kurang dalam perawatan payudara.

\section{KESIMPULAN}

Berdasarkan hasil penelitian tentang hubungan pengetahuan ibu hamil tentang perawatan payudara terhadap sikap perawatan payudara saat kehamilan di Puskesmas XIII Koto Kampar tahun 2018 sebagai berikut:

a. Tingkat pengetahuan ibu hamil di Puskesmas XIII Koto Kampar dengan 21 responden dengan kriteria baik sebanyak 15 orang dengan presentase $71,4 \%$.

b. Sikap perawatan payudara pada ibu hamil di Puskesmas XIII Koto Kampar dengan 21 responden dengan kriteria baik sebanyak 12 orang dengan presentase 57,1\%.

c. Ada hubungannya karena hasil yang di dapatkan dari penelitian $\rho$ value lebih kecil dari nilai signifikan 0,05 , dengan menggunakan chi-square nilai $\rho$ value $=11.550^{\mathrm{a}}$ sehingga $\mathrm{p}$ value $=$ 0,003 dengan $\rho$ value $<\alpha$ yaitu $0,003<0,05$

\section{Ucapan Terima Kasih}

Penulis mengucapkan terimakasih kepada Kepala Puskesmas XIII Koto Kampar yang telah memberikan dukungan terhadap penelitian ini. 


\section{REFERENSI}

Dinas Kesehatan Provinsi Riau. (2014). Profil Kesehatan Provinsi Riau. Pekanbaru : Pemerintah Provinsi Riau.

Manuaba. (2010). Ilmu Kebidanan,Penyakit Kandungan dan KeluargaBerencana Untuk Pendidikan Bidan. Jakarta: EGC

Nugroho, T., Nurrezki., D,Warnaliza., dan Wilis. (2014). Asuhan kebidanan 3 nifas. Ed 1. Nuha Medika: Yogyakarta

Nurhati, M. (2009). Kehamilan Dan Persiapan Persalinan. Jakarta : Garamond, 10-12.

Rahayu, N. E. (2012). HubunganAntara Tingkat Pengetahuandengan Perilaku Ibu Hamil TentangPerawtan Payudara di Poli Kandungan RSUD Dr. Harjono Ponorogo. Skripsi Universitas Muhammadiyah Ponorogo

Saryono dan Pramitasari, R.D. (2009). Perawatan Payudara. Jogjakarta : Mitra Cendikia Offset, 57-78.

Wulandarai, V. (2012). Hubungan Antara Tingkat Pengetahuan Ibu Primigravida Dengan Perilaku Perawatan Payudara Saat Hamil. Diakses Tanggal 08 Desember 2018. http://eprints.ums.ac.id>naskah_publikasi_vika 